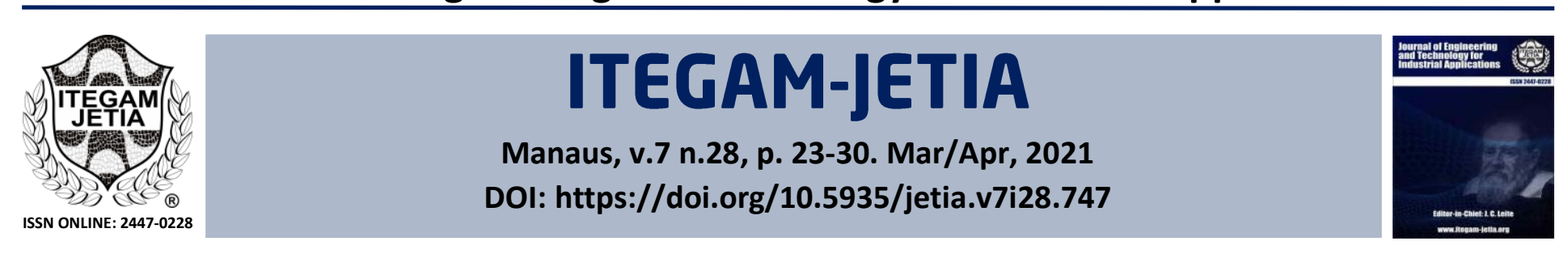

\title{
ANALYSIS OF POWER QUALITY PARAMETERS AT COMPARING UPS OF DIFFERENT TECHNOLOGIES
}

\author{
Rafael Provenzano Jou Alves ${ }^{1}$, André Abel Augusto ${ }^{2}$ and Márcio Zamboti Fortes*3 \\ ${ }^{1,2,3}$ Fluminense Federal University (UFF). Niterói, Rio de Janeiro, Brasil. \\ ${ }^{1}$ http://orcid.org/0000-0001-6124-8315 @ ${ }^{2}{ }^{2}$ http://orcid.org/0000-0001-7171-3372 @ ${ }^{3}$ http://orcid.org/0000-0003-4040-8126 @i
}

Email: rafaelpja@id.uff.br, aaaugusto@id.uff.br, *mzamboti@id.uff.br

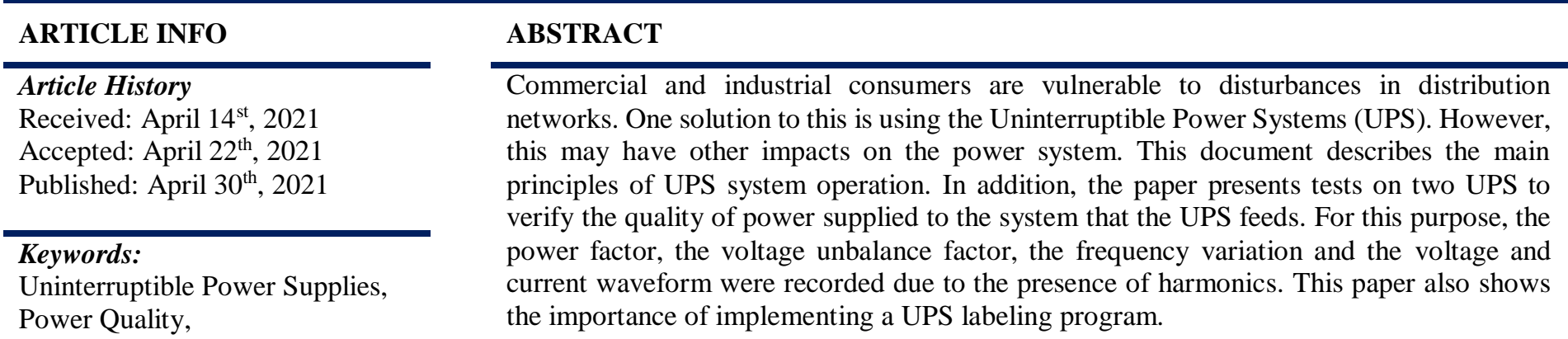

UPS Comparison.

Copyright @ 2016 by authors and Galileo Institute of Technology and Education of the Amazon (ITEGAM). This work is licensed under the Creative Commons Attribution International License (CC BY 4.0).

\section{INTRODUCTION}

In some sectors, such as telecommunications, Information Technology (IT), health, transportation, financial, industry and energy, there are some tools which are essential to operating uninterrupted, an aim to prevent them from being harmed by consumers [1].

In order to improve the power quality and consequently reduce the impact caused due to the poor quality in the power supply in their equipment, the industries seek the efficient installation of energy. To protect their belongings some devices are used. The devices are as UPS, dynamic voltage regulator of static compensation of energy distribution and unified power quality conditioner (UPQC) [2]. In this way, it gives to electric power suppliers the certainty of some determinism of the form of consumption and protection of their investments [3].

To protect processes and equipment that are sensitive to network parameters, many consumers have the option of using UPS, ensuring continuity in the source supports.

With the technological evolution and to meet the needs of the load, UPS units were created with three types of technology. These technologies can be classified as: online, offline and interactive. This article will show the main characteristics of each technology, as well as its advantages and drawback.

Because the UPS is a non-linear load, it can cause harmonic distortions of voltage and current in the network. In addition, it can impact other parameters of the power quality. Therefore, it is necessary to analyze the impacts caused by the UPS in the network and how is the quality of power provided by these units the load.

Despite the growth in UPS usage in the Brazilian market, these devices still need improvement. UPS with low-quality components are still found in the Brazilian market. The consequence of this is low-quality UPS that can affect both the distribution network and the load it feeds. In order to reduce the presence of these UPSs in Brazil, a labeling program is suggested with quality levels to be achieved by the manufacturers.

The following sections are divided into Section II, which briefly describes the components of the UPS system, the classification of technologies, and classification of the topology. Also in this section, it presents the definition of power quality and the standards in Brazil. Section III presents the scenario to which the tests performed in this article were executed and then Section IV shows the results obtained and the analysis of such results. Finally, Section V brings the conclusions found in this article.

\section{LITERATURE REVIEW}

\section{II.1 UNINTERRUPTIBLE POWER SUPPLY}

A UPS is, typically, made up of a rectifier, inverter, a batteries bank, automatic transfer switches (ATS), and static transfer switches (STS). It works as an emergency power supply 
embedded in a grid to generate continuous and stable electricity, especially for those environments where a power supply is generally erratic or uninterruptible power supply is highly required [4].

Batteries are important for energy back-up in a UPS. The capacity and life of a battery depend on several factors such as charging mode, temperature, maintenance and use time [5]. At present, rechargeable batteries use technologies such as valveregulated lead-acid (VRLA), nickel-cadmium (Ni-Cd) or lead-acid batteries (LABs) [4].

The use of the inverter in the UPS system requires care because besides adjusting the phase angle and magnitude of the output voltage of the system, it can also be used to help improve some power quality parameters [6].

\section{II.1.1 Classification of UPS}

\section{- Online UPS system}

In online UPS system, the inverter is always active and there are no transfer delays between the external power source and the battery bank and only uses the battery bank in the absence of power, thus avoiding problems such as very high voltages or very low voltages. By doing double conversion it generates a sine wave with perfect output no matter how the wave is at the input. It is recommended for very sensitive loads that require continuous and uninterrupted power, such as hospital equipment, data centers, and servers.

This type of technology has some advantages. The fact that the load is continuously fed by the inverter, so there is no delay due to the transfer time. The output voltage of the UPS is regulated resulting in a low harmonic voltage distortion rate. In addition, grid disturbances do not reach the load. Another interesting point is the use of a static switch, causing an increase in UPS reliability.

On the other hand, it has a low performance, as the converters are cascaded. In addition, it has a high cost as well as its sized due to the rectifier that is dimensioned to power the inverter plus the battery charge.

\section{- Offline UPS system}

In the offline UPS, your inverter remains off while the power supplying the loads is provided by the AC lines. However, when the power distribution network fails, the UPS makes use of the pre-charged batteries to continue supplying power while the batteries are being charged. In these UPS models, there is a transfer delay that is usually a few milliseconds, a time required to power the UPS inverter. It is recommended for homes, businesses, and offices.

The use of UPS of this type of technology presents some benefits like the high efficiency, this because the inverter can operate with no load or off. Another interesting point is its lower cost, compared to online technology UPS, as well as its size, this is a consequence of the battery charger being independent.

Despite the benefits cited, the offline UPS system has a voltage regulation at low load, besides a lack of conditioning of the input current, which can cause an injection of harmonics in the system's electrical network when the loads are non-linear, taking as a consequence a square waveform in the output voltage. Transfer time between the network-to-inverter and the network-inverter modes can be a problem because this can cause zero voltage on the load at these times.

\section{- Interactive UPS System}

The interactive UPS system features a static switch, bidirectional converter/inverter, and battery bank in your system.
During normal operation, power is supplied to the load through the distribution network while the bi-directional converter/inverter charges the battery bank. When there is a fault in the AC lines, the static switch disconnects the load from the distribution network and the converter/inverter feeds the load.

Interactive UPS has the advantages of low cost and higher yield. In addition, it presents the possibility of regulating the output voltage or compensating the harmonics of the load current, allowing the input of the converter to be close to a sinusoid.

The main disadvantage of this type of UPS is that the presence of the inductor does not allow the output voltage and the input voltage to be in phase, generating a transient when the switch is used in the by-pass mode.

\section{II.1.2 Topology-Based Classification}

In order to meet the requirements of the load, there are a variety of configurations of the UPS system. Thus the UPS system can be classified as the configuration of the topology and its circuit. The UPS system may be transformer-based, transformer-less, or high-frequency transformer based. In the literature, the reference [7] it is possible to have a detail on the topic.

\section{2 POWER QUALITY(PQ)}

There are several definitions regarding the concept of PQ. This paper will be based on the concept that "Power quality encompasses the characteristics of the electricity at a given point on an electrical system, evaluated against a set of reference technical parameters" [8]. PQ issues can be viewed in two perspectives one is on the utility side and the other is customer perspective. In the view of utility perspective it relates to system reliability and in the view of the customer, it is an event that is manifested with current, voltage and frequency [9].

One of the known PQ disturbances is voltage events like voltage dips, rapid voltage changes (RVC), swells and interruptions [10]. Although a large volume of data is not available for comparison, based on available literature, there is considerable evidence to suggest that voltage harmonic levels measured on Australian electricity distribution networks are lower than those observed in Europe. There is also limited evidence to suggest that these Australian harmonic levels may be significantly higher than those observed in other regions such as Asia and South America [11].

In Brazil, ANEEL (National Agency for Electric Energy) elaborated PRODIST (Distribution Procedures). These documents present standards related to the technical activities related to the operation and performance of the electricity distribution systems. The topic of electric PQ is addressed in its module 8 . This module considers the following aspects of steady state PQ:

- Voltage at steady state - the voltage contracted at power distribution company at the connection points for accessories complying with a nominal operating voltage of more than $1 \mathrm{kV}$ must be between $95 \%$ and $105 \%$ of the nominal system voltage at the connection point and still coincide with the nominal voltage of one of the branch terminals previously required or recommended for the transformer of the consumer unit. In case the voltage contracted at the connection point by the access or served is equal to or less than $1 \mathrm{kV}$, it must be the rated voltage of the system [12].

- Power Factor (PF) - The PF value must be calculated from the active and reactive power registers $(\mathrm{P}, \mathrm{Q})$ or respective energies (active energy - AE, reactive energy - RE), using the following equations: 


$$
f p=\frac{P}{\sqrt{P^{2}+Q^{2}}}=\frac{A E}{\sqrt{A E^{2}+R E^{2}}}
$$

- Harmonic Distortions - are phenomena related to the deformation in the waveforms of the voltages and currents in relation to the sine wave of the fundamental frequency [12]. The Total Harmonic Distortion (THD) is defined as the total amount of harmonics relative to the fundamental and can be calculated using the equation below up to the 31st harmonic, where the inverter low pass filter typically eliminates other higher order harmonics [13].

$$
T H D \%=\frac{\sqrt{\sum_{n=3,5, \ldots}^{31} V_{n}^{2}}}{V_{1}} \times 100
$$

- Voltage unbalance - occurs when a difference between the amplitudes in the three phase voltages of a three-phase system, and/or in the electrical phase-shift of $120^{\circ}$ between the phase voltages of the same system is verified. This unbalance is calculated from the following mathematical formulation [12]:

$$
\begin{gathered}
V U \%=100 \sqrt{\frac{1-\sqrt{3-6 \beta}}{1+\sqrt{3-6 \beta}}} \\
\beta=\frac{\mathrm{V}_{\mathrm{ab}}{ }^{4}+\mathrm{V}_{\mathrm{bc}}{ }^{4}+\mathrm{V}_{\mathrm{ca}}{ }^{4}}{\left(\mathrm{~V}_{\mathrm{ab}}{ }^{2}+\mathrm{V}_{\mathrm{bc}}{ }^{2}+\mathrm{V}_{\mathrm{ca}}\right)^{2}}
\end{gathered}
$$

Where Vab, Vbc, Vca are line voltage of the phases a, b and $\mathrm{c}$

- Voltage fluctuation - is characterized by the random, repetitive or sporadic variation of the peak value of the instantaneous voltage.

- Frequency variation - the distribution system and the generation facilities connected to it must, under normal operating conditions and on a steady state, operate within the frequency range between $59.9 \mathrm{~Hz}$ and $60.1 \mathrm{~Hz}[12]$.

\section{TESTS}

In order to analyze the PQ provided by two distinct UPS, were recorded: voltage and current waveforms and, consequently, the harmonic voltage distortion present in the system; the PF; the voltage unbalance and the frequency variation.

UPS A has a nominal power of $75 \mathrm{kVA}$, with three-phase input and output at $380 \mathrm{~V}$ and rated frequency of $60 \mathrm{~Hz}$. This UPS supply power a research lab, where it exhibits a capacitive load characteristic. The UPS connection features technology that is classified as offline.

The UPS B has a rated power of 40kVA, as well as the UPS $\mathrm{A}$, has input and output three-phase at $380 \mathrm{~V}$ and rated frequency of $60 \mathrm{~Hz}$. A data center is feed by that UPS. Due to the need for the load, UPS uses online technology.

In order to compare the quality of power supplied to the system by UPS of different technologies, two tests were performed on each UPS. In the first moment were verified the parameters of energy that is supplied to UPS, that is, originating from the power distribution company. The second measurement was made from the output of the UPS, that is, the power that is supplied to the system. Figure 1 shows how the measurement was made at the input of UPS A. Above the UPS is located the PQ analyzer. This equipment measures and records current, voltage, power and THD of voltage and current. The coils used are Rogowski coils. They are meant to measure currents. The wires connected to the circuit breaker and the neutral and ground rods are used to measure the voltages.

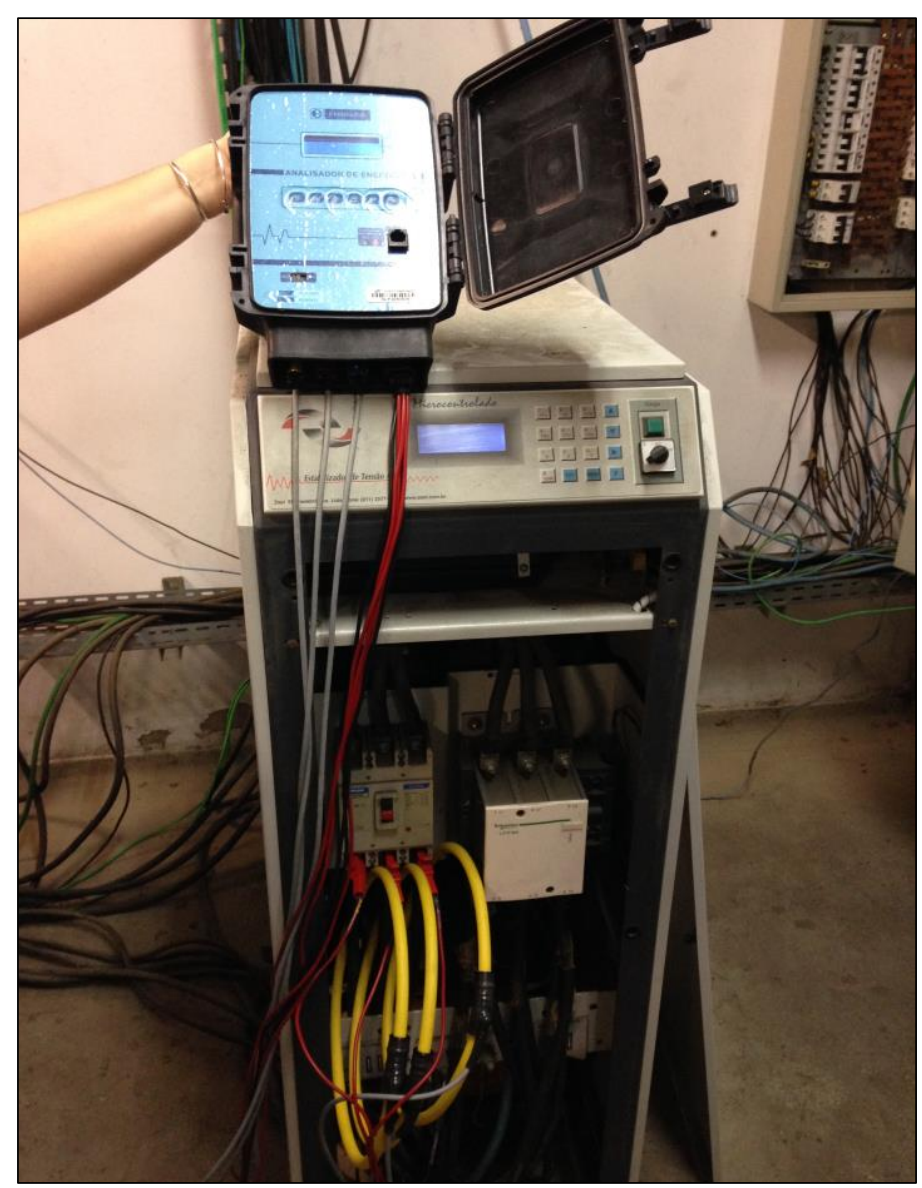

Figure 1: Measurement on UPS A.

Source: Authors, (2021).

\section{RESULTS ANALYSIS}

Figures 2 to 9 show the results of the measurements made during the test period. The graphics were taken from the PQ analyzer software. Figures 2 to 5 belong to UPS A while Figures 6 to 9 refer to UPS B.

Figure 2 shows the waveform of the input voltage at UPS A from top to bottom in phases $\mathrm{A}, \mathrm{B}$ and $\mathrm{C}$ respectively. It is possible to observe that there is no significant harmonic distortion. A THD of $3.03 \%$ was recorded in phase A, $2.63 \%$ in phase B and $3.10 \%$ in phase C. Figure 3 represents the wave, and its harmonic distortion, of the input current of the UPS. During the measurement period, the waveform presented a THD of $25.64 \%$ in phase A, $22.87 \%$ in phase $\mathrm{B}$ and $23.43 \%$ in phase $\mathrm{C}$, where the harmonics of $3 \mathrm{rd}$ were mainly highlighted, but there was a large register of 5th and 7th order harmonics. Regarding the PF, the value of 0.95 capacitive was recorded. As for the voltage unbalance factor, the value was $1.52 \%$. The frequency varied around $59.94 \mathrm{~Hz}$. 


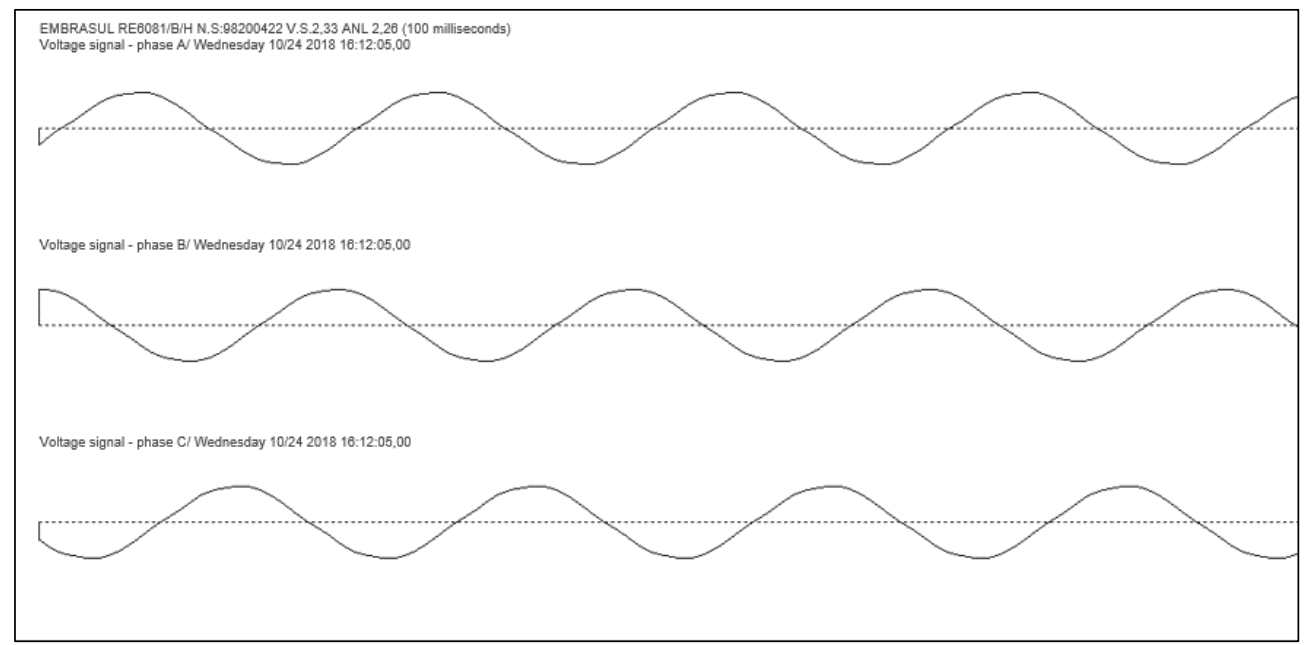

Figure 2: Voltage input to UPS A.

Source: Authors, (2021).

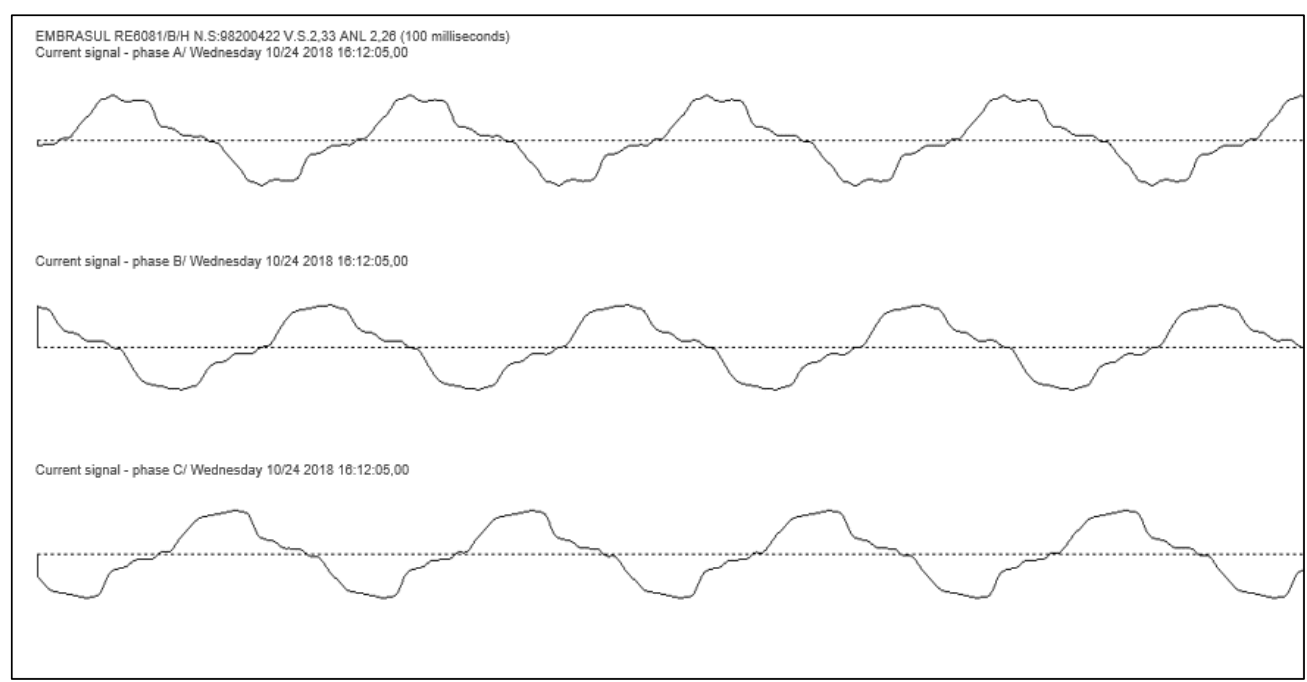

Figure 3: Current input to UPS A.

Source: Authors, (2021).

Figure 4 shows the output voltage waveform of UPS A in phases A, B, and C. As shown in Figure 2, there is no significant harmonic distortion. The THD values do not differ much in relation to the input voltage of the UPS, being $2.92 \%$ in phase A, $2.59 \%$ in phase $\mathrm{B}, 3.01 \%$ in phase $\mathrm{C}$. Table 1 presents a comparison between the individual orders of the input and output voltage harmonics A. The values are given are $\%$ of the fundamental.

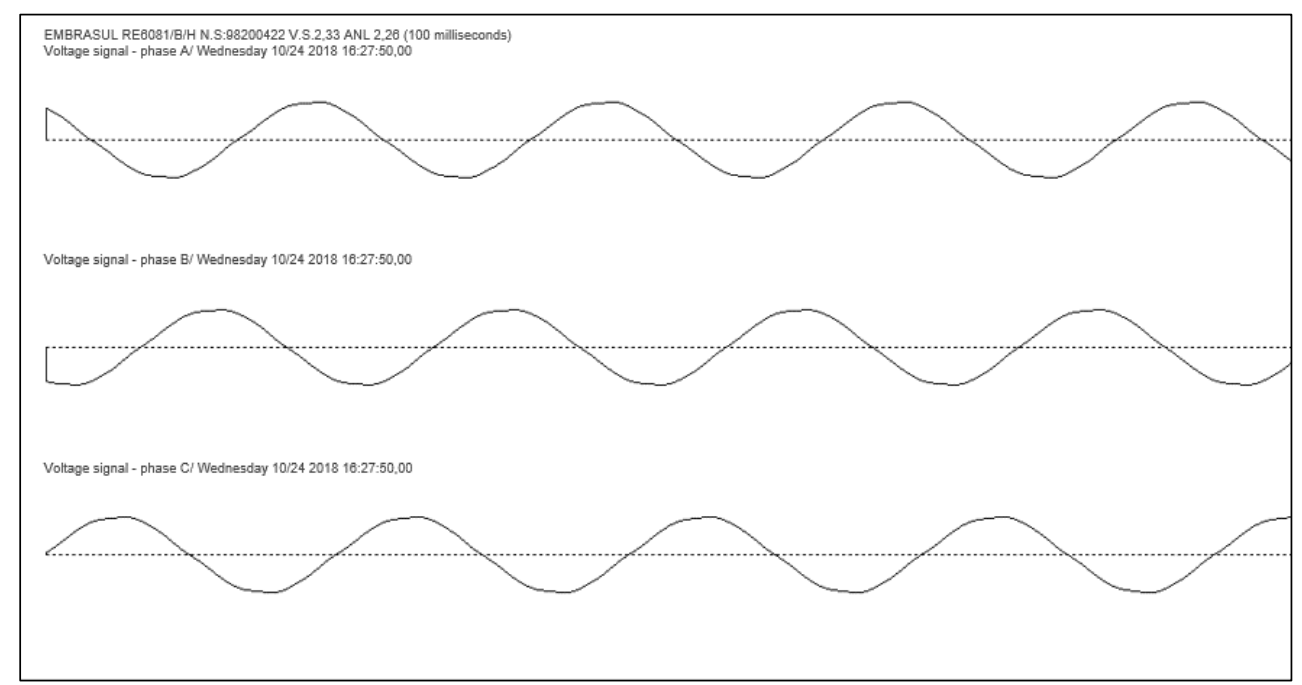

Figure 4: Voltage output from UPS A.

Source: Authors, (2021). 
Table1: Comparison of the voltage of UPS A.

\begin{tabular}{|c|c|c|c|c|c|c|}
\hline \multirow{2}{*}{$\begin{array}{c}\text { Harmonic } \\
\text { Order }\end{array}$} & \multicolumn{3}{|c|}{ Voltage Input UPS A } & \multicolumn{3}{c|}{ Voltage Output UPS A } \\
\cline { 2 - 7 } & $\begin{array}{c}\text { Phase } \\
\text { A }\end{array}$ & Phase B & Phase C & Phase A & Phase B & Phase C \\
\hline 3 & 1.93 & 1.56 & 2,12 & 1.47 & 1.09 & 1.56 \\
\hline 5 & 1.93 & 1.97 & 2,04 & 2.08 & 2.13 & 2.27 \\
\hline 7 & 1.06 & 0.74 & 0,97 & 1.06 & 0.66 & 0.97 \\
\hline 9 & 0.74 & & & 0.94 & 0.71 & 0.66 \\
\hline
\end{tabular}

Source: Authors, (2021).
The waveform of the UPS output current is shown in Figure 5. The recorded THD values are $24.62 \%$ in phase A, $25.13 \%$ in phase B and $21.77 \%$ in phase C. Although not there is a very significant difference in the total values of harmonic distortion, there is a variation in the harmonics order. Table 2 shows a comparison of the harmonic currents of the input and output of the UPS, with values referring to\% of the fundamental order.

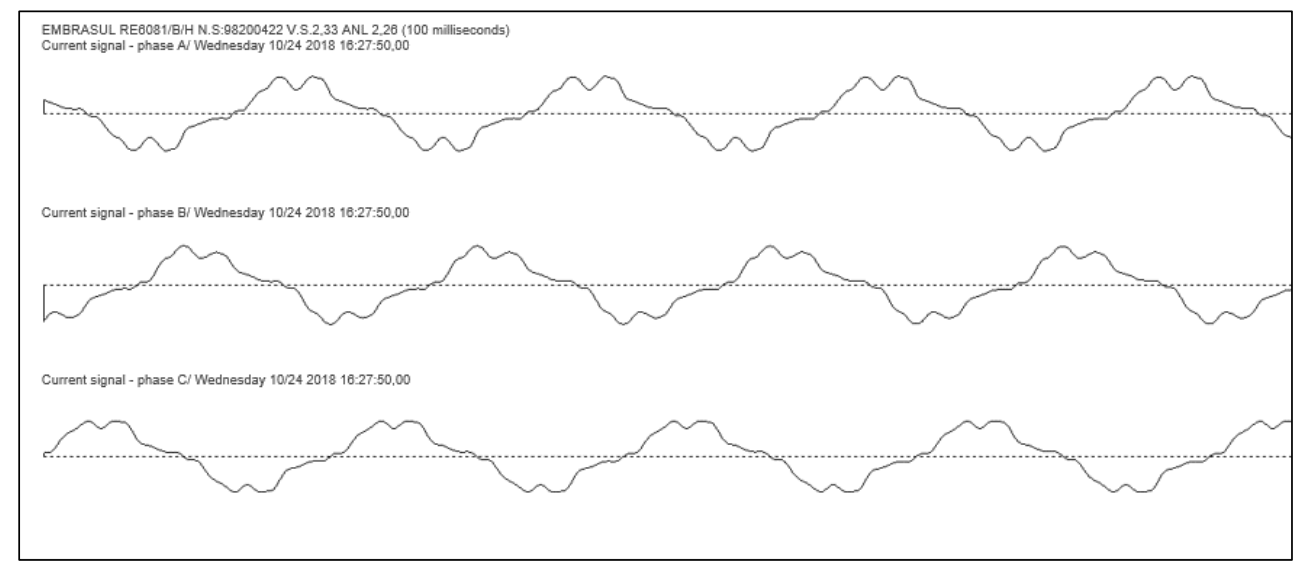

Figure 5: Current output from UPS A.

Source: Authors, (2021).

The reduction of 3rd order harmonics occurred due to the presence of low-pass filters inside the UPS since the increase of harmonic distortion of 5th, 7th and 9th order originated due to the presence of some electronic components contained in the UPS that resonate with the load, resulting in an increase of these harmonic components.

Table 2: Comparison of the current of UPS A.

\begin{tabular}{|c|c|c|c|c|c|c|}
\hline \multirow{2}{*}{$\begin{array}{c}\text { Harmonic } \\
\text { Order }\end{array}$} & \multicolumn{3}{|c|}{ Current Input UPS A } & \multicolumn{3}{|c|}{ Current Output UPS A } \\
\hline & $\begin{array}{c}\text { Phase } \\
\text { A }\end{array}$ & Phase B & $\begin{array}{c}\text { Phase } \\
\text { C }\end{array}$ & $\begin{array}{c}\text { Phase } \\
\text { A }\end{array}$ & Phase B & Phase C \\
\hline 3 & 22.89 & 20.16 & 20.56 & 13.44 & 18.74 & 16.30 \\
\hline 5 & 7.41 & 8.35 & 7.85 & 15.09 & 12.85 & 10.26 \\
\hline 7 & 6.06 & 5.10 & 6.00 & 10.93 & 7.89 & 7.61 \\
\hline 9 & 4.27 & 0.87 & 2.02 & 6.91 & 4.83 & 3.61 \\
\hline 11 & 2.81 & 3.61 & 3.16 & 2.76 & 3.27 & 2.94 \\
\hline 13 & 2.70 & 2.28 & 3.18 & 3.8 & 3.73 & 4.41 \\
\hline 15 & 0.78 & & & & 1.26 & 1.02 \\
\hline 17 & 2.46 & 0.91 & 1.62 & 2.34 & 1.52 & 1.51 \\
\hline 19 & & & & 0.80 & & \\
\hline 21 & & 0.79 & 0.70 & & & \\
\hline 23 & 1.20 & & 0.87 & 1.38 & 0.91 & \\
\hline
\end{tabular}

Considering the other PQ parameters, the measured PF was 0.95 capacitive. Regarding the voltage unbalance factor, it registered $3.91 \%$. The frequency variation was around $59.94 \mathrm{~Hz}$.

The waveform in the voltage input of the UPS B is represented in Figure 6. In this, it is possible to observe that the harmonic distortion of the wave is insignificant. The THD recording was $3.11 \%$ in phase $\mathrm{A}, 3.36 \%$ in phase $\mathrm{B}$ and $3.50 \%$ in phase C. Figure 7 shows the waveform of the input current in UPS B. Through these curves it is possible to observe a large harmonic distortion in the current wave received from the utility. The measurement shows a THD of $33.89 \%$ in phase A, $46.92 \%$ in phase $\mathrm{B}$ and $23.31 \%$ in phase C. In these registers there was a predominance of 3rd and 5th order harmonics. With regard to the $\mathrm{PF}$, the value of 0.99 was recorded. The voltage unbalance factor was $0.11 \%$. Regarding the frequency variation was around $60.06 \mathrm{~Hz}$.

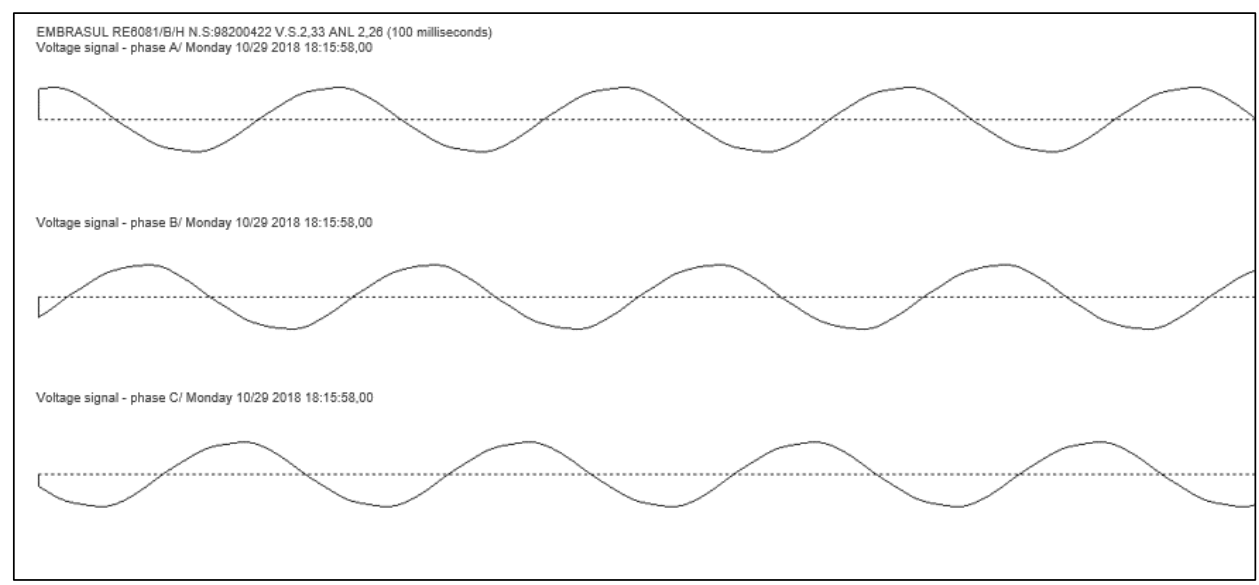

Figure 6: Voltage input to UPS B.

Source: Authors, (2021). 


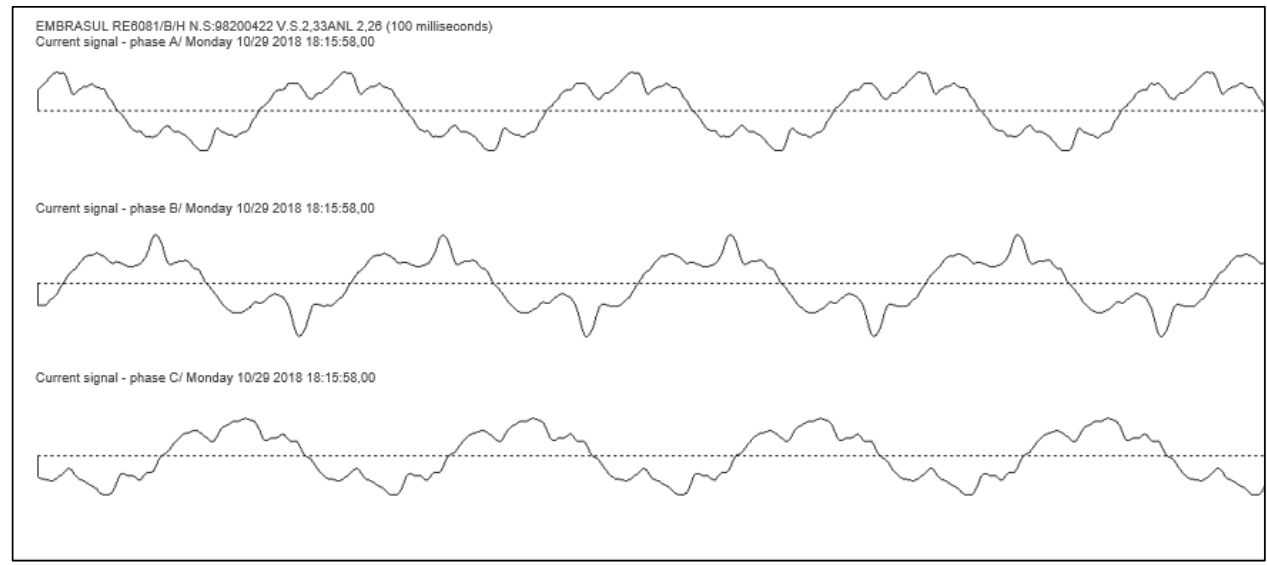

Figure 7: Current input to UPS B.

Source: Authors, (2021).

According to Figure 8 and according to the registered in the PQ analyzer, the waveform of the voltage at the output of UPS B, there was practically no harmonic occurrence in the voltage supplied by the UPS to the system. The THD of phases A and C was zero, whereas in phase B there was a THD of $0.87 \%$. Table 3 presents the comparison of the harmonic orders of the UPS input and output, having their values as $\%$ of the fundamental.

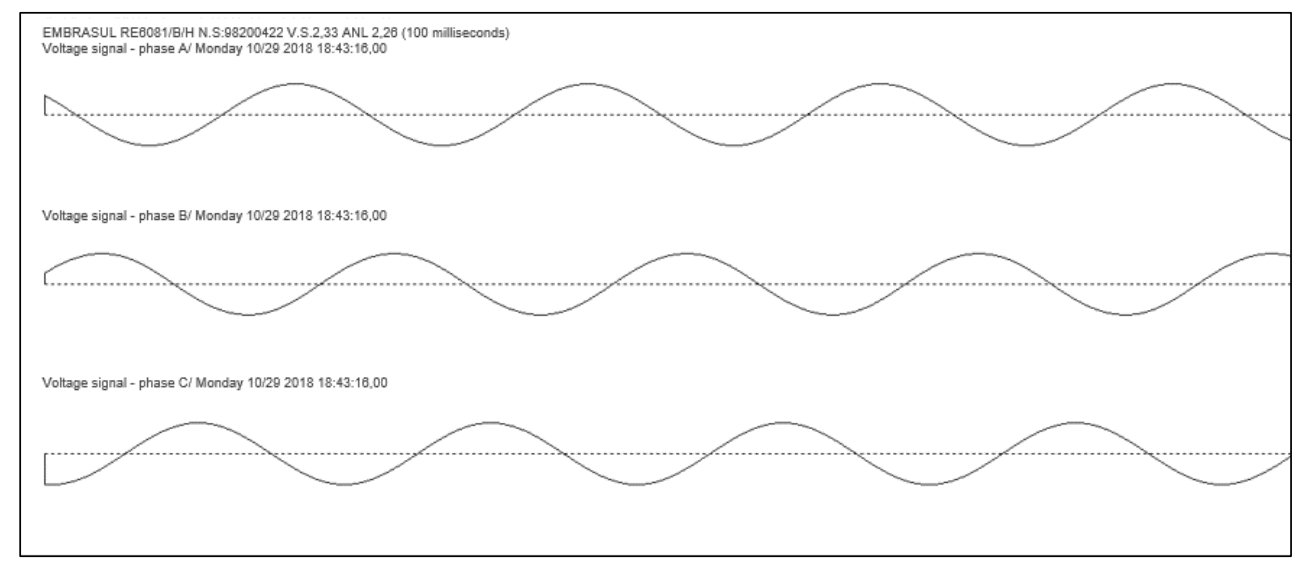

Figure 8: Voltage output from UPS B.

Source: Authors, (2021).

Figure 9 shows the waveform of the current at the output of the UPS B. Through this figure it is possible to observe a significant improvement in the waveform. The THD of 5.93\% in phase A, $7.20 \%$ in phase B and $5.79 \%$ in phase C, actually prove this improvement. The filters in the UPS are responsible for improving the PQ in this measurement. Table 4 shows the contrast between the harmonic orders of the UPS input and output. The values presented are $\%$ relative to the fundamental.
Table 3: Comparison of the voltage of UPS B.

\begin{tabular}{|c|c|c|c|c|c|c|}
\hline \multirow{2}{*}{$\begin{array}{c}\text { Harmonic } \\
\text { Order }\end{array}$} & \multicolumn{3}{|c|}{ Voltage Input UPS B } & \multicolumn{3}{c|}{ Voltage Output UPS B } \\
\cline { 2 - 7 } & $\begin{array}{c}\text { Phase } \\
\text { A }\end{array}$ & Phase B & $\begin{array}{c}\text { Phase } \\
\text { C }\end{array}$ & $\begin{array}{c}\text { Phase } \\
\text { A }\end{array}$ & Phase B & Phase C \\
\hline 3 & 2.54 & 2.85 & 3.08 & & 0.87 & \\
\hline 5 & 1.49 & 1.45 & 1.38 & & & \\
\hline 7 & 0.97 & 0.72 & 0.89 & & & \\
\hline 9 & \multicolumn{7}{|c|}{0.68} & & & & \\
\hline
\end{tabular}

Source: Authors, (2021).

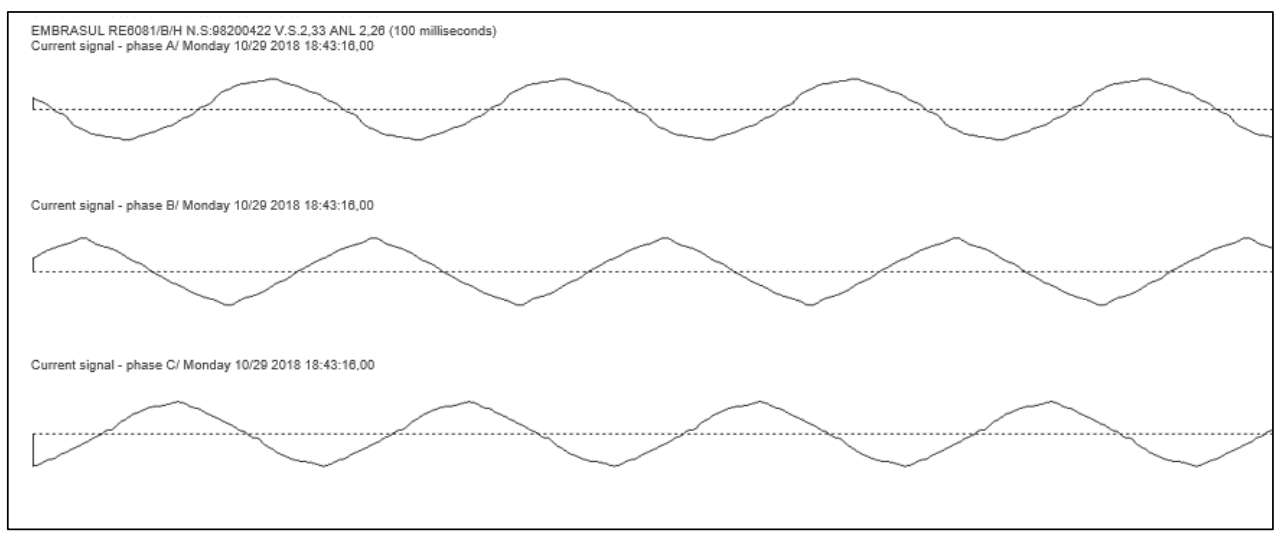

Figure 9: Current output from UPS B.

Source: Authors, (2021). 
Table 4: Comparison of the current of UPS B.

\begin{tabular}{|c|c|c|c|c|c|c|}
\hline \multirow[b]{2}{*}{$\begin{array}{c}\text { Harmonic } \\
\text { Order }\end{array}$} & \multicolumn{3}{|c|}{ Current Input UPS B } & \multicolumn{3}{|c|}{ Current Output UPS B } \\
\hline & $\begin{array}{c}\text { Phase } \\
\text { A }\end{array}$ & Phase B & $\begin{array}{c}\text { Phase } \\
\text { C }\end{array}$ & $\begin{array}{c}\text { Phase } \\
\text { A }\end{array}$ & Phase B & Phase C \\
\hline 3 & 21.22 & 35.15 & 12.73 & 4.09 & 5.62 & 4.24 \\
\hline 5 & 21.31 & 20.47 & 22.05 & 2.61 & 2.63 & 2.51 \\
\hline 7 & 11.50 & 15.59 & 4.91 & 2.23 & 1.60 & 2.12 \\
\hline 9 & 4.42 & 13.38 & 6.49 & & 2.75 & 0.47 \\
\hline 11 & 6.13 & 6.66 & 5.28 & 1.13 & 1.41 & 1.41 \\
\hline 13 & 2.94 & 4.52 & 1.94 & 1.02 & & 0.58 \\
\hline 15 & 3.27 & 3.63 & 2.91 & 1.70 & 1.03 & 0.66 \\
\hline 17 & 1.42 & 1.46 & & 1.13 & & \\
\hline 19 & 2.32 & & 2.21 & & & 0.82 \\
\hline 21 & 1.14 & 0.76 & 2.00 & & & 0.66 \\
\hline 23 & 2.37 & 0.95 & 2.39 & & & 0.51 \\
\hline 25 & 0.97 & 1.51 & & & & 0.55 \\
\hline 31 & 1.23 & 1.00 & & & & \\
\hline 39 & 0.66 & & & & & \\
\hline 41 & 0.76 & & & & & \\
\hline
\end{tabular}

Regarding the other PQ parameters analyzed at the output of UPS B, the power factor value of 0.97 was recorded. As for the voltage unbalance factor, the value was $0.09 \%$. Regarding the frequency variation, the value was registered around $60.00 \mathrm{~Hz}$.

Tables 5 to 9 present a comparison between UPS A and B and compare them with the minimum indicators described in the PRODIST. Although a minimum indication was not specified in the PRODIST, a comparison was made between the current THD of the two UPS. It is possible to observe that the records made in the measurements are according to the PRODIST, except for the voltage unbalance factor of the UPS A.

Table 5: Comparison of PF.

\begin{tabular}{|c|c|c|}
\hline PRODIST & Output UPS A & Output UPS B \\
\hline $0.92<P F<1.00$ & 0.95 & 0.97 \\
\hline \multicolumn{3}{|c|}{ Source: Authors, (2021). } \\
\hline
\end{tabular}

Table 6: Comparison of Voltage THD.

\begin{tabular}{|c|c|c|c|c|c|c|}
\hline \multirow{2}{*}{ PRODIST } & \multicolumn{3}{|c|}{ Voltage Output UPS A in } & \multicolumn{3}{c|}{ Voltage Output UPS B in \% } \\
\cline { 2 - 7 } & $\begin{array}{c}\text { Phase } \\
\text { A }\end{array}$ & Phase B & $\begin{array}{c}\text { Phase } \\
\text { C }\end{array}$ & $\begin{array}{c}\text { Phase } \\
\text { A }\end{array}$ & Phase B & Phase C \\
\hline THD $<10 \%$ & 2.92 & 2.59 & 3.01 & 0 & 0.87 & 0 \\
\hline \multicolumn{3}{|c}{ Source: Authors, (2021). }
\end{tabular}

Table 7: Comparison of current THD.

\begin{tabular}{|c|c|c|c|c|c|}
\hline \multicolumn{2}{|c|}{ Current Output UPS A in \% } & \multicolumn{3}{c|}{ Current Output UPS B in \% } \\
\hline Phase A & Phase B & Phase C & Phase A & Phase B & Phase C \\
\hline 24.62 & 25.13 & 21.77 & 5.93 & 7.20 & 5.79 \\
\hline
\end{tabular}

Source: Authors, (2021).

Table 8: Comparison of unbalance voltage.

\begin{tabular}{|c|c|c|}
\hline PRODIST & Output UPS A & Output UPS B \\
\hline UV < 3.0\% & $3.91 \%$ & $0.09 \%$ \\
\hline \multicolumn{3}{|c}{ Source: Authors, (2021). }
\end{tabular}

Table 9: Comparison of frequency variation.

\begin{tabular}{|c|c|c|}
\hline PRODIST & Output UPS A & Output UPS B \\
\hline $59.9<f<60.1$ & 59.94 & 60.00 \\
\hline \multicolumn{3}{|c}{ Source: Authors, $(2021)$. }
\end{tabular}

When comparing the two UPS, although both are in accordance with the PRODIST indicators, except for the voltage unbalance factor of UPS A, we can observe that in UPS B there is an effective improvement in the quality of power supplied to the system through the UPS. Already with the use of UPS A, we cannot see any improvement, especially regarding the harmonic content provided to the system. This difference in PQ provided by the UPS to the system is due to the classification of the technology present on the UPS is installed.

In order to have greater transparency vis-à-vis the consumer, as far as UPS is concerned with improving the system and reducing the number of low-quality products on the market, Brazilian public policy may adopt a UPS labeling program. This would stimulate the increase in the quality of the products in terms of energy efficiency and the quality of energy supplied. As suggested in the reference [14].

\section{CONCLUSION}

The growing need for quality energy supplies means that there is a continuous growth in the use of UPS for this purpose. This article shows the relevance of UPS in the quality of power supply. In addition, it shows the importance of the topology classification that the UPS is installed to meet the customer's goal. So if you want to use the UPS to increase the PQ of the system you should install the UPS online. If you install the UPS offline, you will not be able to see an improvement in the quality of the power, and may even make it worse. Another important point that the article shows is that the UPS tested are in accordance with some PQ parameters specified by ANEEL.

In Brazil, UPS consumes about $1.7 \%$ of energy production. This percentage represents $8,529,286 \mathrm{MWh}$, which presents losses of about $1,006,790 \mathrm{MWh}$, i.e., $11.8 \%$ of the total energy consumed by UPS is losses [14]. Therefore, an efficient labeling program with adequate supervision can increase the quality of the equipment on the market and consequently reduce UPS consumption losses.

Through this article, it is possible to observe the importance of the adopted UPS technology aiming at the sensitivity of the load that this UPS will feed. In addition, this article shows the importance of a UPS labeling program to improve the quality of the equipment supplied on the market.

\section{AUTHOR'S CONTRIBUTION}

Conceptualization: Rafael Provenzano Jou Alves, André Abel Augusto and Márcio Zamboti Fortes.

Methodology: Rafael Provenzano Jou Alves, André Abel Augusto and Márcio Zamboti Fortes.

Investigation: Rafael Provenzano Jou Alves.

Discussion of results: Rafael Provenzano Jou Alves, André Abel Augusto and Márcio Zamboti Fortes.

Writing - Original Draft: Rafael Provenzano Jou Alves.

Writing - Review and Editing: Rafael Provenzano Jou Alves, André Abel Augusto and Márcio Zamboti Fortes.

Resources: Rafael Provenzano Jou Alves, André Abel Augusto and Fortes.

Supervision: André Abel Augusto and Márcio Zamboti Fortes. Approval of the final text: Rafael Provenzano Jou Alves, André Abel Augusto and Márcio Zamboti Fortes.

\section{REFERENCES}

[1] F. D. Gonçalves, Resposta de Sistemas Ininterruptos de Energia Frente a Fenômenos de Qualidade de Energia, Universidade Federal de Brasília, 2008.

[2] K. Palanisamy, M. K. Mishra, D. P. Kothari, S. Meikandashivam and I. J. Raglend, "Power Quality Improvement and Photovoltaic Module Interconnection using Unified Power Quality Conditioner," Australian Journal of Electrical and Electronics Engineering, vol. 10, no. 2, pp. 183-189, 2013.

[3] K. S. Pediatidakis, Fonte ininterrupta de energia aplicada a sistemas com cargas lineares, Universidade Federal do ABC, 2014. 
[4] X. Zhang, H. Xue, Y. Xu, H. Chen and C. Tan, "An investigation of an uninterruptible power supply (UPS) based on supercapacitor and liquid nitrogen hybridization system," Energy Conversion and Management, vol. 85, pp. 784-792, 2014.

[5] A. Ahmad, M. A. Saqib, S. A. R. Kashif, M. Y. Javed, A. Hameed and M. U. Khan, "Impact of wide-spread use of uninterruptible power supplies on Pakistan's power system," Energy Policy, vol. 98, pp. 629-636, 2016.

[6] R. Ghanizadeh and G. B. Gharehpetian, "Distributed hierarchical control structure for voltage harmonic compensation and harmonic current sharing in isolated MicroGrids," Sustainable Energy, Grids and Networks, vol. 16, pp. 55-69, 2018.

[7] M. Aamir, K. A. Kalwar and S. Mekhilef, "Review: Uninterruptible Power Supply (UPS) system," Renewable and Sustainable Energy Reviews, vol. 58, pp. 1395-1410, 2016.

[8] G. V. d. Broeck, J. Stuyts and J. Driesen, "A critical review of power quality standards and definitions applied to DC microgrids," Applied Energy, vol. 229, pp. 281-288, 2018.

[9] S. Rajeshbabu and B. V. Manikandan, "Detection and classification of power quality events by expert system using analytic hierarchy method," Cognitive Systems Research, no. 52, pp. 729-740, 2018.

[10] M. Jasiński, T. Sikorski and K. Borkowski, "Clustering as a tool to support the assessment of power quality in electrical power networks with distributed generation in the mining industry," Electric Power Systems Research, vol. 166, pp. $52-60,2019$

[11] S. Elphick, V. Smith, V. Gosbell and S. Perera, "Characteristics of Power Quality Disturbances in Australia: Voltage Harmonics," Australian Journal of Electrical and Electronics Engineering, vol. 10, no. 4, pp. 490-496, 2013.

[12] ANEEL, "PRODIST," $10 \quad 01$ 2017. [Online]. Available: http://www.aneel.gov.br/prodist. [Accessed 2011 2018].

[13] A. K. Al-Othman, H. Tamer and Abdelhamid, "Elimination of harmonics in multilevel inverters with non-equal dc sources using PSO," Energy Conversion and Management, vol. 50, no. 3, pp. 756-764, 2009.

[14] I. L. Sauer, H. Tatizawa and F. A. Salotti, "Power quality and energy efficiency assessment and the need for labelling and minimum performance standard of uninterruptible power systems (UPS) in Brazil," Energy Policy, vol. 41, pp. 885$892,2012$. 